\title{
Elmanuscrito literario en la época de su (multi)reproductibilidad técnica
}

Emiliano Mastache ${ }^{1}$

Incluso en la más perfecta de las reproducciones una cosa queda fuera de ella: el aqui y el ahora de la obra de arte, su existencia única en el lugar donde se encuentra.

Walter Benjamin

La repetición no modifica nada en el objeto que se repite, pero cambia algo en el espíritu que la contempla.

David Hume

La obra es un gran espacio vacio o en construcción que siempre se está llenando de nuevos contenidos, de nuevas imágenes. En este sentido, podríamos decir: cuanto más grande es un maestro, más vacía está su obra. Es un significante sin identidad que se llena constantemente de nuevos significados. El origen se muestra como una construcción posterior.

Byung Chul Han

Los manuscritos de El libro vacío ${ }^{2}$

EL LIBRO VACÍO SE PUBLICÓ EN 1958 Y ES LA PRIMERA NOVELA DE LA ESCRITORA MEXICANA JOSEFINA VICENS. ${ }^{3}$ La novela recibió el Premio "Xavier Villaurrutia” ese mismo año. La importancia de dicho reconocimiento radica en que únicamente dos escritores lo habían recibido antes: Juan Rulfo, por Pedro Páramo, en 1955; y Octavio Paz, por El arco y la lira, en 1956 -en 1957, el premio fue declarado desierto.

De igual modo, cabe decir que la novela trata sobre un hombre de mediana edad y mediana condición, de nombre José García, que se enfrenta al inexplicable e imperioso deseo de escribir. Para ello se dará a la tarea de intentarlo en un cuaderno; no obstante, no llegará a lograr su cometido. La novela da cuenta de ese tortuoso e intrincado periplo.

${ }^{1}$ Doctor en Literatura Comparada por la Universidad del Estado de Río de Janeiro, Brasil. Actualmente es Becario del Programa de Becas Posdoctorales en la UNAM, en el Instituto de Investigaciones Filológicas. Sus líneas de investigación son: crítica genética, archivos y manuscritos literarios, literatura latinoamericana y literaturas en lengua portuguesa. Entre sus publicaciones más importantes, se encuentran: el libro Un soplo de vida: La escritura de Clarice Lispector, pensamiento del afuera (2015), y artículos diversos y capítulos en libros sobre autores como Juan Gelman, Nicanor Parra, Reinaldo Arenas, Clarice Lispector y Josefina Vicens. Contacto: emiliano_mastache@yahoo.com

${ }^{2}$ Para una breve historia de la noción de "manuscrito", véase: Hay, Louis. "La escritura viva”, en LoIs, É. (coord.). Filología. Número especial dedicado a la Crítica Genética. Año XXVII, 1-2. Buenos Aires: Instituto de Filología y Literaturas Hispánicas "Dr. Amado Alonso", 1996, pp. 5-22.

${ }^{3}$ Josefina Vicens sólo publicaría una segunda novela, llamada Los años falsos, más de veinte años después, en 1982. 
Ahora bien, no fue sino hasta hace un par de años que los manuscritos de El libro vacío -se trata de dos cuadernos escritos a mano por Josefina Vicens- fueron puestos a mi disposición para su conocimiento, estudio y eventual difusión. ${ }^{4}$

Las características generales de los dos cuadernos son las siguientes:

- Miden aproximadamente $15 \mathrm{~cm}$. x $20 \mathrm{~cm}$. y poseen el mismo tamaño.

- Las hojas son de papel bond, blancas y cuentan con rayado horizontal impreso en azul claro.

- Se trata de cuadernos cosidos.

- Los cantos aparecen con segmentos simétricos de diferentes colores (ese tipo de cuadernos solía utilizarse en el ámbito contable o de oficina).

- Poseen capas duras.

- El primero de ellos se distingue por tener las capas de color azul; cuenta con 59 folios con contenido susceptible de ser transcrito; en la dedicatoria que se encuentra al interior de la capa inicial está datado, de puño y letra de la autora, en el año 1954.

- El segundo cuaderno tiene las capas de color rojo; cuenta con poco más de 150 folios con contenido susceptible de ser transcrito; se encuentra datado, a mano, por la autora, en el año de 1958, también en una dedicatoria. ${ }^{5}$

Como se puede advertir, a partir de las dataciones es posible afirmar que la creación de la novela le llevó a Josefina Vicens, por lo menos, cuatro años.

Ahora bien, la importancia de dicho material es simplemente extraordinaria. En primer lugar, debido a la nula existencia de ese tipo de documentos en el ámbito de la literatura mexicana, tal y como lo advierte Alejandro Higashi:

En general, la tardía consolidación de un concepto de autor profesional en las letras mexicanas se ha traducido en la pérdida de una buena parte de los manuscritos autógrafos y dossiers que podrían servir para reconstruir el proceso creador detrás de una obra, y no son escasas las noticias sobre asaltos y otros abusos sufridos por los autores o sus familiares durante los episodios más violentos de nuestra historia nacional. Mientras para la mayor parte de los novelistas franceses y alemanes decimonónicos contamos con varios testimonios manuscritos autógrafos (casi siempre borradores en los que pueden deducirse distintas campañas escriturales para revivir el proceso de redacción previo a la editio princeps), para nuestros autores mexicanos apenas podemos presumir de unos pocos manuscritos autógrafos, aunque a menudo se trata de copias en limpio, como pasa con el cuadernillo de Fernández de Lizardi editado por Nancy Vogeley, en parte, o con el autógrafo de El Zarco de Altamirano. ${ }^{6}$

\footnotetext{
${ }^{4}$ Dicho material se encuentra en resguardo particular y no es susceptible de consulta pública. Esta circunstancia, como se verá adelante, imposibilitó su estudio y transcripción durante el extenso período que abarcó la pandemia.

${ }^{5}$ Un aspecto singular de los dos cuadernos es que cada uno cuenta con una dedicatoria realizada a mano y firmada por la autora, en la cara interna de cada capa inicial; lo cual es algo poco común para un manuscrito literario.

${ }^{6}$ Higashi, A. Perfiles para una ecdótica nacional. Crítica textual de obras mexicanas de los siglos XIX y XX, México, UNAM/UAM, 2013, p. 254. Para el caso del siglo XX, existen documentos autógrafos de autores como Juan Rulfo, Alfonso Reyes, Jorge Ibargüengoitia, Salvador Elizondo o Rosario Castellanos.
} 
En segundo lugar, la importancia de los manuscritos radica en que se trata de una escritora que no ha recibido la atención que merece. Pero, finalmente y, sobre todo, su relevancia descansa en que dicho material había permanecido inédito y desconocido durante más de seis décadas hasta fechas recientes.

Con base en lo anterior, la elaboración de una edición genética se fue consolidando paulatinamente como un objetivo natural, además de que representaba una oportunidad incomparable de otorgar a la obra y a su autora el reconocimiento que a una y otra corresponde en el ámbito de la literatura mexicana.

Hasta aquí la descripción del corpus documental y de la obra. A continuación se exponen algunos aspectos de la investigación que actualmente se encuentra en curso en relación con los manuscritos de El libro vacío.

\section{Hacia una edición genética de El libro vacío}

Una vez que se tuvo acceso a los manuscritos de la primera novela de Josefina Vicens, se comenzó a desarrollar un proyecto de investigación con miras a la realización de una eventual edición genética de los mismos. Dicho proyecto de investigación fue aceptado para una estancia posdoctoral con duración de dos años, actualmente en curso.

En correspondencia con las características del material, el proyecto se subdividió en dos partes: un año se dedicaría al estudio y análisis del primer cuaderno manuscrito; y el otro año, al segundo cuaderno. El objetivo final planteado, en ambos casos, consiste en la realización de la transcripción de cada uno de los cuadernos. Ahora bien, la razón para proponer como meta la transcripción y no una edición genética propiamente dicha, se debió, sobre todo, al hecho de que, desde un origen, fue sumamente evidente que la realización de una edición genética iba a requerir al menos tres o cuatro años, dada la vasta complejidad inherente a los manuscritos; y por supuesto, también a los plazos de la investigación. En otras palabras, desde un inicio se concibió la realización de la transcripción de los dos cuadernos como el primer paso hacia una eventual edición genética; es decir, como una especie de fase heurística de carácter primario. ${ }^{7}$

Ahora bien, el tipo de transcripción a realizar sería de carácter paleográfico; esto es, una transcripción que, a un mismo tiempo, fuera lo más fiel posible al original y que evitara cualquier intervención ajena a la autora. ${ }^{8}$

Finalmente, el marco teórico propuesto para la investigación se caracterizó por ser una perspectiva centrada en las discontinuidades de la escritura así como en las materialidades y las corporeidades que intervienen en la misma.

\footnotetext{
${ }^{7}$ La edición científica de un texto se constituye a través de dos fases elementales: una primera fase heurística y una posterior fase hermenéutica. Tal y como lo plantea Élida Lois, "editar e interpretar procesos de escritura son dos actividades complementarias: editar génesis representa una propuesta de lectura, y con ello se está adelantando un primer intento de interpretación. Y al mismo tiempo, es imposible acceder a la etapa interpretativa sin haber transitado por una reconstrucción de la escritura que permita leerla sin dificultad." LoIs, É. Génesis de escritura y estudios culturales. Buenos Aires: Edicial, 2001, p. 5.

${ }^{8}$ El carácter paleográfico de una transcripción radica en la capacidad de descifrar la escritura de uno o varios documentos, con el fin de desentrañar su sentido y significado; es decir, se da primacía a la dimensión verbal por sobre los demás aspectos. La paleografía, en última instancia, es una disciplina histórica que tiene como propósito estudiar las transformaciones de la escritura a través del tiempo y ser capaz de situar sus diversas manifestaciones en una determinada época y circunstancia.
} 
Respecto de la primera cuestión, optar por una visión centrada en las discontinuidades -antes que en la reconstrucción del proceso de escritura, tal y como lo dictaría la crítica genética tradicional-, , surgió a partir de los planteamientos hechos por los geneticistas brasileños Claudia Pino y Roberto Zular, en su libro: Escrever sobre escrever. Uma introdução crítica à crítica genética. Los autores hacen notar que es precisamente a través de la observación y detección de las discontinuidades en un manuscrito que se podrán delimitar con precisión los enunciados que van conformando la progresión de la escritura, lo cual redunda en una mejor y más precisa delimitación de las campañas que la van conformando. Así, fue a partir de esa perspectiva general que se emprendió la transcripción del primer cuaderno manuscrito de El libro vacío.

A continuación se exponen las fases que atravesó dicho proceso; no sin tener siempre presente que, en última instancia, es virtualmente imposible llegar, desde una perspectiva crítico-genética, a una metodología definitiva en la medida en que "cada manuscrito suele requerir una solución propia". ${ }^{10}$ Es decir, no sólo es infructuoso sino probablemente contraproducente pretender aproximarse a un determinado manuscrito con una perspectiva o una visión preestablecidas. Un acercamiento semejante corre el riesgo de distorsionar los fenómenos que le son intrínsecos. De manera que, por decirlo de algún modo, es fundamental dejar que el propio manuscrito "hable" y muestre, progresivamente, aquellos aspectos que le son constitutivos y estructurales; cometido que sólo podrá alcanzarse con dedicación y paciencia a través de diversas etapas.

\section{Fases de la transcripción}

La primera fase consistió en llevar a cabo la lectura íntegra del documento con miras a una comprensión general. Así, los dos primeros meses de la investigación se dedicaron a la lectura del primer cuaderno de los manuscritos de El libro vacío, con la correspondiente toma de notas.

La segunda fase consistió en realizar una primera transcripción de carácter tentativo, en la cual se privilegió lo legible sobre lo ilegible. Dicha transcripción se llevó a cabo en un soporte electrónico. ${ }^{11}$ Así, se transcribieron en una primera versión o borrador todos aquellos términos que no presentaran ningún tipo de duda y se dejaron para un momento posterior todos aquellos términos que presentaban dificultades. Esta labor se realizó durante el primer semestre de la investigación. Por desgracia, las graves circunstancias de salud hicieron que la consulta

\footnotetext{
${ }^{9}$ Al respecto: "En la base de esa utopía, los geneticistas presentan la noción de proceso, entendido como reconstrucción de las etapas de creación.” PINO, C. y ZULAR, R. Escrever sobre escrever. Uma introdução crítica à crítica genética. São Paulo: WMF Martins Fontes, 2007, p. 27. En portugués en el original: "Na base dessa utopia, os geneticistas apresentam a noção de processo, entendido como uma reconstrução das etapas de criação." Con negritas en el original. (La traducción es mía).

${ }^{10}$ En el original: “cada manuscrito requerer uma solução própria.”. (La traducción es mía). Ibídem, p. VIII.

${ }^{11}$ Esta decisión obedeció a la distinción básica hecha por Élida Lois entre la edición genética en soporte-papel y la edición electrónica. Si bien la autora considera como "propiamente genética” a la primera, con respecto a la segunda afirma: "ninguna edición en soporte papel lograría restituir el espacio, el tiempo y la atmósfera de la creación como las referencias visuales, sonoras y espectaculares convocadas a esos efectos en la edición electrónica.” LOIS, É. Op. cit., p. 57. En consecuencia, desde el primer momento busqué entrevistarme con diversas personas del ámbito editorial y académico con el objeto de explorar una posible edición digital de los manuscritos. A través de varias entrevistas reconocí la posibilidad y la importancia de incursionar por esa vía para el trabajo, no obstante, el surgimiento de la pandemia impidió que pudiera darse seguimiento a esa posibilidad.
} 
de los manuscritos se volviera inviable y a partir de ahí, la transcripción entró en un desafortunado impasse. En tales condiciones, la única actividad posible fue emprender, en al menos tres ocasiones distintas durante los meses subsecuentes, la revisión de los avances con que se contaba hasta ese momento.

Ahora bien, en origen, como se mencionó, la transcripción se concibió como paleográfica, es decir, como una transcripción que procurara ser lo más fiel posible al original y que evitara cualquier intervención ajena al autor. La razón radica en que esa primera transcripción habría de constituirse en la base para la eventual interpretación del manuscrito -esto es, la subsecuente "fase hermenéutica". Así, dicha transcripción se asumió, antes que como un método de fijación textual, como la forma primigenia de desciframiento del documento y de delimitación de criterios fundamentales. Ahora, en estricto sentido, dicho ejercicio se corresponde con la tercera fase que, según Élida Lois, es parte del proceso de conformación de un dossier genético. Dicha autora sostiene que la constitución de un dossier genético se compone de nueve fases: 1) localización del todo el material posible; 2) datación; 3) desciframiento; 4) transcripción; 5) doble clasificación cronológica (de los manuscritos y las lecciones); 6) doble clasificación tipológica (de los manuscritos y de las lecciones); 7) reorganización de todo el material; 8) descripción del material recopilado; 9) análisis (en realidad, "microanálisis"). ${ }^{12}$

Como ya se ha mencionado, el corpus está conformado únicamente por dos cuadernos manuscritos -que ya han sido debidamente descritos con su respectiva datación- de manera que la conformación del dossier genético se limita a la existencia de dichos materiales. ${ }^{13}$

Ahora, si bien es cierto que en el trabajo con un manuscrito se privilegia la dimensión textual, en tanto el objeto primordial es su contenido, generalmente suelen hacerse presentes otras dimensiones que, a primera vista, pueden no parecer importantes. Así, durante más de dos meses se centró la atención, de manera casi exclusiva, en transcribir las palabras en el procesador de textos electrónico. Empero, muy pronto fue claro que las tachaduras y marcas que la propia Josefina Vicens había realizado en las diversas páginas del cuaderno obstaculizaban el desciframiento textual en buena parte del manuscrito. No obstante, al mismo tiempo se fue haciendo cada vez más contundente su importancia en términos del proceso de creación escritural. De modo que la necesidad de transcribirlas con el mismo cuidado que cada una de las palabras se volvió indiscutible. En consecuencia, se procedió a la reproducción tanto de la dimensión verbal como de las tachaduras, procurando que fueran lo más fiel posible al original, tanto en su forma y extensión como en el trazo y en la proporción que guardan con la dimensión textual.

En otras palabras, lo que en principio se había concebido como una transcripción paleográfica había demostrado ser insuficiente, por lo cual se dio paso a una transcripción diplomática propiamente dicha. ${ }^{14}$

\footnotetext{
${ }^{12}$ LOIS, E. Op. cit., p. 5.

${ }^{13}$ Hasta este momento no se tiene conocimiento de ningún otro documento en relación con El libro vacío, sea de carácter "pre-redaccional: planos, escenarios generales, programa o proyecto de argumentos, notas, esbozos, croquis, esquemas, apuntes, etcétera; o redaccional: manifestaciones que presentan una propuesta textual en marcha: borradores.” RAMÍREZ, I. "Genética y crítica textuales en la edición de obras contemporáneas." En: CLARK, B. et al (orgs.). Crítica textual: un enfoque multidisciplinario para la edición de textos. México, Colmex-UNAM, 2009, p. 212. Más allá, vale la pena recordar que la propia Josefina Vicens, a punto de entregarlo a la editorial, extravió el manuscrito final de la novela en un florería, aunque logró recuperarlo días después -seguramente se trataba de un mecanuscrito y no, propiamente, de una versión hecha a mano.

${ }^{14}$ Fernando Colla la define de la siguiente manera: "Se trata de una transcripción de tipo "diplomático", es decir, que reproduce las características espaciales y formales de la secuencia escritural: el tachado aparece imitado (actualmente los procesadores de texto permiten utilizar fácilmente este recurso), y la segunda enmienda aparece en su posición original, en
} 
Optar por una cabal transcripción diplomática, que incluyera tanto la dimensión verbal como de las tachaduras, obedeció al hecho de que durante la realización de la primera transcripción, se fue haciendo notorio que presentar únicamente la reproducción del texto daría lugar a múltiples confusiones en tanto creaba lagunas de indeterminación, en vez de propiciar un entendimiento claro de los eventos escriturales, las campañas y el proceso de creación en general. Es decir, si se optaba por realizar una transcripción puramente textual, que dejara de lado las tachaduras, no sólo se producía la falsa impresión de un continuum, en momentos diversos, sino que, además, impedía advertir con propiedad los cortes en la escritura y podía provocar que se leyeran como un solo enunciado trechos que, en el original, se habían suscitado de manera entrecortada o como reelaboraciones de un mismo trecho. ${ }^{15}$

De tal forma, las tachaduras constituyen un aspecto fundamental del proceso de escritura en el primer cuaderno manuscrito de El libro vacío de Josefina Vicens, en la medida en que conforman un índice inequívoco de los momentos en que la autora se detuvo, descartó parte de lo que venía escribiendo y propuso variantes. En consecuencia, ignorar este aspecto en la transcripción sería inadecuado porque deformaría ostensiblemente el manuscrito original.

En esto radica una las primeras particularidades de la primera tentativa de transcripción del primer cuaderno de El libro vacío de Josefina Vicens; en el hecho de que procuró reproducir todas las marcas no verbales que aparecen en el manuscrito.

Así, la tercera fase se dedicó a la reproducción de todas las tachaduras correspondientes encima de la transcripción que se venía elaborando en el procesador de textos. Ahora, como se podrá deducir, llevar a cabo la reproducción de las tachaduras fue arduo y complejo, no sólo por las condiciones mismas del manuscrito, sino porque se hizo en un soporte electrónico: contar únicamente con el mouse terminó convirtiéndose en una labor titánica. No obstante, fue una de las decisiones más atinadas en el proceso de transcripción, no sólo porque ello satisfacía el carácter diplomático de la misma, sino porque ese paciente y minucioso quehacer de reproducción hizo posible una comprensión novedosa y aún más profunda del manuscrito.

Así, al momento en que se impuso el confinamiento, habían sido transcritas 40 hojas del cuaderno (el 60\% aproximadamente), tanto en su dimensión verbal como en su dimensión gráfica (marcas, tachaduras, etc.).

Ahora bien, la cuarta fase de la transcripción no surgió enseguida, por el contrario, demoró en hacerse presente. Esto se debe a que durante muchos meses fue imposible avanzar en la transcripción debido a las circunstancias descritas. Con el paso de los meses tanto el manuscrito como el proceso de transcripción realizado habían comenzado a desdibujarse -me refiero a aquellos detalles, aspectos e inercias profundas que naturalmente afloran y se van consolidando con la continuidad del trabajo y del trato recurrente con un documento.

el interlineado superior." COLLA, F. "La edición genética: entre la profusión y la mesura”. En: ColLA, F. (comp.). Archivos. Cómo editar la literatura latinoamericana del siglo XX. Poitiers: Centre de Recherches Latino-Americaines, CRLA Archivos, 2005, p. 162. Como se puede observar, la distinción fundamental entre una transcripción paleográfica y una transcripción diplomática, sin que necesariamente sean dos cosas distintas, consiste en que en el caso de la primera, como ya se ha hecho notar, la atención se centra en la escritura; y en el caso de la segunda, tal y como se la comprende desde la crítica genética, se toman en cuenta otros aspectos además de la dimensión verbal.

${ }^{15}$ Más adelante se presentan dos imágenes de un mismo fragmento de la transcripción: la primera es exclusivamente textual (sin tachaduras); y la segunda incluye todas las marcas no verbales conforme al original (con tachaduras). Las diferencias entre una y otra versión son evidentes. 
No obstante, fue bajo esas condiciones que se hizo presente una idea que si bien puede parecer inocua, demostró ser altamente productiva. Me refiero a emprender -tal y como en la antigüedad lo hacía un amanuense- la copia, a mano, de lo que hasta ese momento había transcrito. O lo que puede entenderse como una transcripción apógrafa. Esta actividad, por una parte, hizo posible reanudar el contacto con el contenido del documento y, a la larga, reactivar el estudio y el proceso de reflexión respecto al mismo. En segundo lugar, me permitió emprender una aproximación distinta al manuscrito, a partir de la cual comenzaron a hacerse manifiestos algunos aspectos del proceso de creación de El libro vacío que no habían sido advertidos o que no habían sido debidamente apreciados. Finalmente, me proporcionó los criterios definitivos para la transcripción final.

En ese sentido, si bien no fue sencillo copiar manualmente parte de las hojas que se tenían ya transcritas, dicho ejercicio marcó un antes y un después en el devenir tanto de la investigación como de la propia transcripción. Los hallazgos fueron de tal magnitud que de inmediato reconocí que sería de suma importancia copiar, directamente del original, algunas partes.

En esto consistieron la quinta y sexta fases de la transcripción: en copiar manualmente, primero, parte de las páginas que ya habían sido transcritas en formato electrónico, es decir, a partir de la pantalla del computador. Y en un segundo momento, una vez que me fue posible consultar de nuevo el manuscrito, en copiar a mano directamente del primer cuaderno, partes del original.

Los beneficios fueron múltiples y sumamente valiosos. Cabe destacar, además de los ya mencionados, el hecho de que al escribir a mano ciertos pasajes fue posible descifrar algunos términos que habían permanecido en condición de "ilegibles" hasta ese momento. De igual forma, comenzaron a hacerse evidentes, con mucha mayor precisión, el alcance y la extensión de los diversos períodos de escritura, gracias a los cortes o rupturas sintácticas que se suscitan en el devenir de las líneas del manuscrito.

Ahora bien, como se mencionó al principio, este último aspecto posee una profunda correspondencia con el marco teórico propuesto desde un origen: una perspectiva centrada en las discontinuidades. La razón es muy puntual. Tal y como lo plantean Claudia Pino y Roberto Zular: "una vez encontrada, esa discontinuidad servirá como instrumento para delimitar otro objeto: el enunciado. La única forma de definirlo sería por su bordes, o sea, por sus rupturas con otros enunciados."16

No obstante, cabe preguntar:

¿Pero qué sería un enunciado? Foucault rechaza las explicaciones lingüísticas: para él un enunciado no podría ser definido simplemente por sus leyes internas, por ejemplo, sus características gramaticales. Para haber sido proferido, luego transformado en documento y finalmente conservado, fue necesario que alguien lo profiriera, y que esa persona haya estado autorizada a proferirlo, que alguna institución lo haya registrado y que otra lo haya guardado.

\footnotetext{
16 Pino, C. y Zular, R. Op. cit., p. 42. En portugués en el original: "Por outro lado, uma vez encontrada, essa descontinuidade servirá como instrumento para delimitar outro objeto: o enunciado. A única forma de defini-lo seria por suas bordas, ou seja, por suas rupturas com outros enunciados.” (La traducción es mía).
} 
[...] De esa forma, los enunciados no pueden ser entendidos sin las condiciones de su enunciabilidad. $^{17}$

En consecuencia, el término enunciado no lo utilizo en su acepción más común ni en su sentido gramatical especializado, sino que debe entenderse como aquella construcción verbal que, sin poseer necesariamente un significado completo o pleno, se distingue de todas aquellas construcciones verbales que están presentes a su alrededor, previa o posteriormente, precisamente porque no hay una relación de continuidad semántica o sintáctica entre ellas. Así, un enunciado puede ser toda frase, palabra o período verbal que se disloca de un continuum y adquiere, con ello, cierto grado de autonomía, no sólo a nivel semántico sino también en su grafismo; es decir, se distingue visual y espacialmente.

Todo esto desemboca en lo que propongo llamar, propiamente, como enunciado de la escritura. Una noción a través de la cual es posible concebir a la propia escritura como la instancia fundamental de enunciación, lo cual encuentra plena correspondencia con uno de los principios que definen a la crítica genética: el postular como objeto de estudio no ya al texto sino a la escritura. ${ }^{18}$

Así, las rupturas y discontinuidades comenzaron a tener una incuestionable centralidad en la comprensión del manuscrito. En ello radica la segunda característica fundamental de la transcripción: en el hecho de que procura destacar esas rupturas y discontinuidades, y con ello, hacer evidente, en la medida de lo posible, cada enunciado de la escritura.

Ahora bien, las discontinuidades se encuentran admirablemente reforzadas a lo largo de las páginas, por al menos otros dos aspectos que son más bien gráficos o visuales que verbales. Y no sobra reiterar que la trascendencia de esos dos aspectos sólo se hizo presente, a cabalidad, a partir de la transcripción apógrafa -la copia manual- de las hojas del manuscrito original.

El primero de ellos consistió en reconocer que hay una asombrosa proporcionalidad entre las palabras escritas por Josefina Vicens, a través de las diversas páginas del manuscrito. Es decir, resulta admirable la simetría casi perfecta que existe entre cada uno de los espacios en blanco que la escritora iba dejando entre cada palabra. Pero, por si no fuera suficiente, la relación de proporción de esos intersticios en blanco se mantiene casi intacta aún cuando la caligrafía, al paso de las diversas hojas, se modifica en múltiples ocasiones. ${ }^{19}$

\footnotetext{
${ }^{17}$ Ídem. En portugués en el original: "Mas o que seria um enunciado? Foucault recusa as explicações linguísticas: para ele um enunciado não poderia ser definido simplesmente pelas suas leis internas, por exemplo, suas características gramaticais. Para que fosse proferido, logro transformado em documento e por fim conservado, foi necessário que alguém o tivesse proferido, que essa pessoa fosse autorizada a proferi-lo, que alguma instituição o tenha registrado e que outra o tenha guardado. [...] Dessa forma, os enunciados não podem ser entendidos sem as condições da sua enunciabilidade." (La traducción es mía).

${ }^{18}$ No es ocioso advertir que esta perspectiva necesariamente se aleja de la noción de voluntad del autor, en la medida en que para el caso de un manuscrito literario, tal voluntad no existe como tal, porque se encuentra, obviamente, en formación. Al respecto, Blecua sostiene: "La crítica textual es el arte que tiene como fin presentar un texto depurado en lo posible de todos aquellos elementos extraños al autor. Deberá atender, en primer lugar, a los errores propios de la copia." BLECUA, A. Manual de crítica textual. Barcelona: Edhasa, 2018, p. 19. Como es obvio, en un manuscrito literario lo más común es que, por definición, no haya "elementos extraños al autor", dado que todos han provenido de él. De ahí la necesidad de optar por una perspectiva crítico-genética y no tanto filológica para el caso de los manuscritos de El libro vacío.

${ }^{19}$ A lo largo del manuscrito hay notorios cambios en la caligrafía de Josefina Vicens, no obstante, no existe una relación de dependencia entre la misma y el proceso de creación.
} 
Ahora, en varios momentos algunos espacios son notoriamente más amplios que el resto, lo cual constituye un signo inequívoco de un corte en la escritura. Y si se observan con atención se advertirá que esos espacios en blanco más amplios son, en realidad, resultado de la propia tachadura, en la medida en que ésta rebasa la extensión del período en cuestión (que puede ser una palabra o una frase, o renglones enteros); esto es, lo excede y se extiende bastante más allá.

En una palabra: la tachadura produce ese espacio en blanco.

[Permítase una variación: la tachadura produce el vacio...]

De manera que ha sido la pausa en la escritura por parte de la autora, luego, la reconsideración de lo escrito, y finalmente la decisión de descartar determinado período tachándolo horizontalmente, lo que ha dado lugar a esos intersticios en blanco, mismos que se encuentran surcados por una línea horizontal que parece buscar extenderse sobre el vacío, sobre esas diminutas formas del vacío que, paradójicamente, han hecho posible, con cada una de sus discretas apariciones, la propia escritura de Josefina Vicens.

Por lo demás, no sobra agregar que estos espacios en blanco más largos, que han surgido gracias a la tachadura, se dan, sin excepción, al interior de un renglón -rara vez al principio o al final de los mismos. Por esta razón se hacen aún más perceptibles en la lectura del manuscrito.

En cualquier caso, su verdadera trascendencia radica en que revelan un movimiento fundamental en la escritura de Josefina Vicens -al menos en lo que respecta al primer cuaderno manuscrito de El libro vacío. Dicho movimiento consiste en el hecho de que la autora, de manera reiterada y sistemática, realizaba tachaduras diversas al momento mismo de ir escribiendo la campaña primigenia de escritura. (De otro modo sería inexplicable que pudieran aparecer, indistintamente, espacios en blanco más extensos que los habituales). Es decir, a lo largo de casi todo el manuscrito se aprecia cómo la autora iba tachando sobre la marcha diversos términos, frases o períodos de escritura, para enseguida encontrar otras soluciones y continuar. Lo cual constituye uno de los aspectos más importantes del documento, en tanto permite sostener que el primer cuaderno manuscrito de El libro vacío se encuentra recorrido mucho más por "variantes de escritura" que por "variantes de lectura". ${ }^{20}$

En correspondencia con estos hallazgos, para la transcripción se puso un esmerado cuidado en reproducir fielmente tanto esos intersticios blancos, como las respectivas tachaduras que los atraviesan, con el propósito de que se puedan no sólo distinguir las discontinuidades en la escritura, sino, sobre todo, advertir, hasta donde esto es posible, cada enunciado de la escritura en el manuscrito. Claro, esto ha significado reproducir meticulosa y pacientemente, para todas las líneas de cada una de las páginas, el resto de los espacios en blanco que, como se ha dicho, comparten una proporcionalidad y una simetría casi perfectas. De manera que cada unas de las tachaduras, así como cada uno de los espacios en blanco -sean los comunes o aquellos que marcan discontinuidades-, deben ser valorados, a lo largo de la transcripción, en la misma exacta medida que cada uno de los términos que conforman la dimensión verbal. Con ello, el carácter diplomático de la transcripción también se concreta a través de la fiel reproducción tanto de los espacios en blanco en su proporcionalidad como

\footnotetext{
${ }^{20}$ De manera puntual: "si se trata de una reescritura inmediata al correr de la pluma -"variante de escritura"- o de una "variante de lectura", introducida después de haber terminado una primera redacción y, en general, después de una relectura." COLLA, F. Op. cit., p. 149-150.
} 
de las tachaduras. Estas tres dimensiones: el texto, las tachaduras y los blancos, son las que, cabalmente, le dieron forma. Y como se podrá advertir, ninguna de las tres puede considerarse más relevante que las otras dos.

Ahora, todo esto no significa que otros aspectos inherentes al manuscrito carezcan de importancia (como el trazo, el grosor del mismo, la caligrafía en sus variaciones o las tintas y colores de los diversos instrumentos de escritura). Por el contrario, también son relevantes. No obstante, en estricto sentido, ninguno de ellos, ya sea en conjunto o por separado, alcanza a tener la misma trascendencia que los tres que fueron privilegiados, dado que no poseen relación de dependencia con el proceso de creación de El libro vacío. Es decir, a diferencia de otros manuscritos en que las tintas o el trazo pueden estar asociados profundamente, por ejemplo: a determinados temas, a partes específicas del manuscrito, a la forma en que el autor concibe las campañas de escritura, en el caso de primer cuaderno manuscrito de El libro vacio de Josefina Vicens, ni el trazo, ni el instrumento de inscripción, ni las tintas encuentran alguna relación con los procesos de escritura en sus diferentes niveles y dimensiones. Por tal motivo, en la transcripción se dejaron en un segundo plano todos esos aspectos; aunque ciertamente, una decisión semejante también se debió a razones de carácter técnico.

Llegado ese momento, se emprendió la transcripción final, con base tanto en el trabajo realizado durante más de un año, como en las diversas versiones de la transcripción con que se contaba hasta ese momento. No obstante, casi de inmediato surgió una nueva e importante dificultad de carácter técnico.

Como se mencionó, el soporte fundamental que se ocupó desde un inicio para la transcripción fue un procesador de textos electrónico común. Asimismo, se señaló que la tercera fase fue dedicada a la minuciosa reproducción de cada una de las marcas y tachaduras, para las páginas que hasta ese momento se tenían transcritas en ese soporte. No obstante, intencionalmente se ha evitado mencionar el hecho de que, durante todo ese tiempo, cada vez que el documento electrónico de la transcripción era abierto, algunas marcas se desacomodaban y había que arreglarlas de nuevo. E incluso, de manera un tanto inexplicable, algunas de esas marcas simplemente habían desaparecido. Desafortunadamente, esto se fue haciendo cada vez más frecuente conforme avanzaba en la transcripción. Tal parece que el procesador de textos se saturaba y no guardaba todos los cambios gráficos que iba añadiendo a cada vez, y esto provocaba que las tachaduras se desajustaran por completo. Así, llegó un momento en que resultó simplemente imposible estar colocando cada marca en su lugar o volver a reproducirla, una y otra vez.

Se recurrió entonces al formato PDF; tal vez así podrían mantenerse las marcas y tachaduras en el lugar indicado. Desafortunadamente, si bien dicho formato lograba resguardar las marcas, las movía unos milímetros de su lugar y con ello era suficiente para desarreglar íntegramente la transcripción.

La importancia de esta cuestión no radica, meramente, en lo anecdótico, sino en la trascendencia que posee el uso de soportes electrónicos y digitales en el trabajo de transcripción de un manuscrito literario; esto es, en lo que hace a su reproductibilidad técnica. Dichos soportes son, sin duda, imprescindibles para una labor de transcripción de un documento. No obstante, para bien o para mal, siempre habrá aspectos y detalles de un manuscrito que, como se ha expuesto, no sólo es sumamente complicado reproducir por vía electrónica, sino que simplemente resulta imposible hacerlo con fidelidad para todos y cada uno de ellos. ${ }^{21}$

\footnotetext{
${ }^{21}$ Por ejemplo, el color de las tintas no necesariamente se puede reproducir con exactitud en el formato electrónico. Asimismo, representa una dificultad si en un trecho se ha hecho uso de dos bolígrafos, con tinta del mismo color, pero con trazo diferente. Eso mismo es lo que sucede con el lápiz en el manuscrito de El libro vacío: en ocasiones, su trazo se va
} 
De esta forma fue como finalmente se llegó a la octava y definitiva última fase del proceso de transcripción. La misma consistió en realizar una reproducción en la que tuvieran cabida, por igual, las diferentes dimensiones, criterios y aspectos que, durante quince meses habían demostrado ser fundamentales. Esto es, por un lado, había que procurar que la transcripción fuese lo más fiel posible al original. En segundo lugar, la transcripción debía privilegiar no sólo la dimensión verbal del manuscrito, sino tratar de reproducir, también, tanto las tachaduras como los espacios en blanco en su justa medida. Finalmente, había que dar cuenta de los instrumentos de inscripción, las tintas y colores de los mismos conforme al original. Todo ello, a partir de una perspectiva crítico-genética centrada en las discontinuidades.

Respecto al primer aspecto, se decidió hacer la transcripción final en el procesador de textos electrónico, íntegramente en color negro, en fuente Times New Roman, procurando reproducir minuciosamente tanto cada uno de los espacios en blanco como la simetría que los caracteriza; así como aquellos espacios en blanco más amplios que marcan un corte en la escritura. ${ }^{22}$

Respecto al segundo aspecto, como se mencionó, las tachaduras realizadas en formato electrónico se desacomodaban constantemente; en consecuencia, se optó por reproducirlas manualmente para cada una de las páginas. Así, una vez que se había traspuesto el texto en el procesador electrónico junto con los espacios en blanco, se procedía a imprimir la página en cuestión, e inmediatamente eran reproducidas, a mano, todas y cada una de las tachaduras, con sumo cuidado: tanto en su forma e inclinación, como en su extensión.

A continuación se presentan dos imágenes de un fragmento de la transcripción. En el primer caso se trata de una transcripción que únicamente contempla la dimensión verbal. En el segundo se han incluido, además, todas las tachaduras conforme al original. Se ha decidido presentarlas de manera conjunta con el fin de facilitar su comparación.

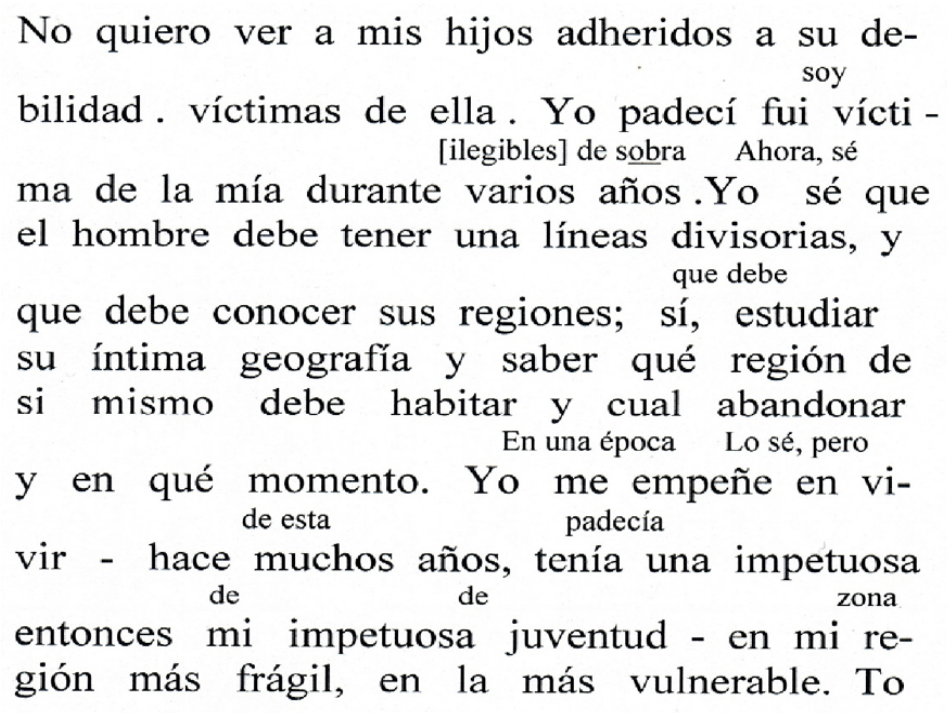

Transcripción fragmento (sólo texto). Cuaderno I, El libro vacio.

haciendo más grueso conforme la punta se desgasta. Y ni qué decir cuando, por ejemplo, encima de la campaña inicial de escritura a lápiz, se ha sobrepuesto otra de corrección, o incluso varias, también a lápiz, pero de trazos más definidos, más oscuros y delgados.

${ }^{22}$ Para la transcripción final, todas las inserciones -escrituras realizadas en un segundo momento- fueron dispuestas, conforme al original, en un renglón aparte, pero aparecen en fuente 11 con el fin de distinguirlas claramente del resto del texto, el cual aparece en fuente 14. 


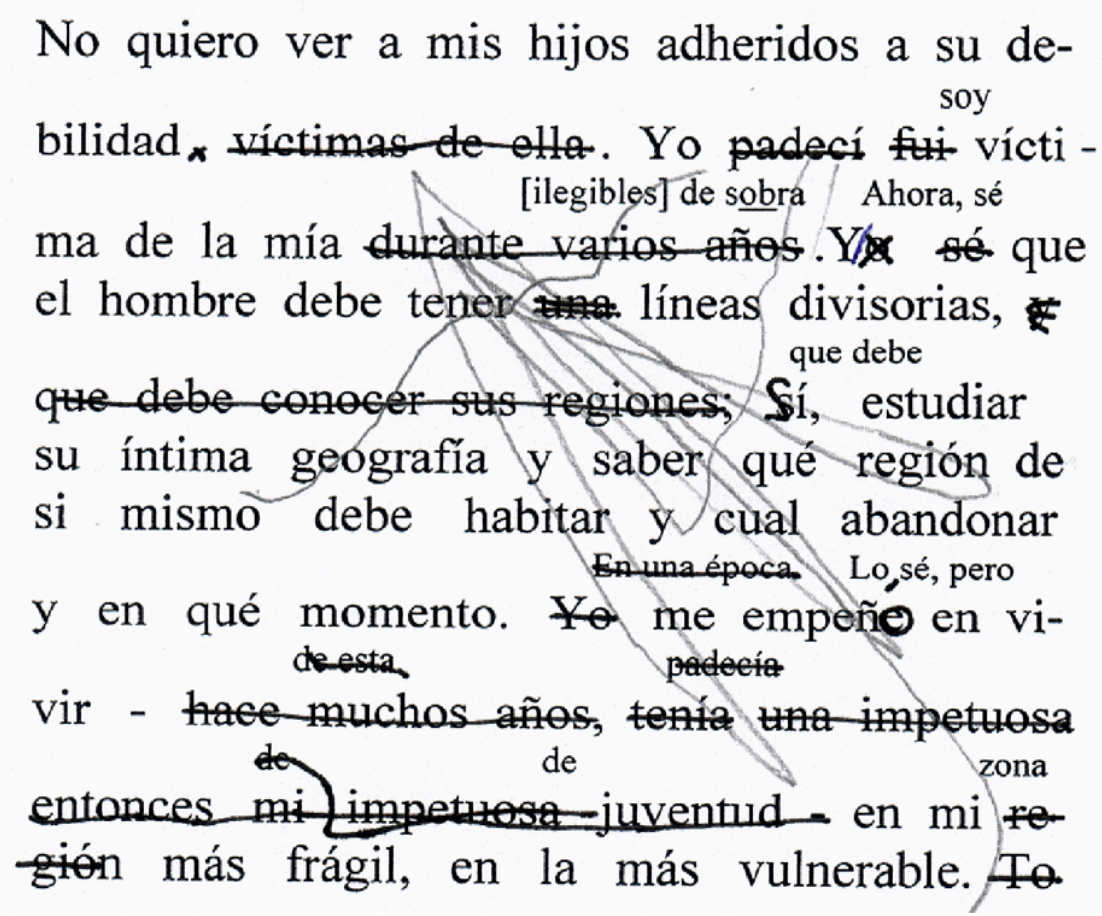

Transcripción con tachaduras. Cuaderno I, El libro vacio.

Finalmente, con el objeto de dejar constancia de los instrumentos de inscripción que intervienen a lo largo del manuscrito, se optó por crear un código que consta de una pequeña tabla para cada página, en la que, de manera sencilla, se da cuenta tanto del o los instrumento(s) de inscripción y la(s) tinta(s) correspondiente(s) que intervienen en la misma. Así, en todo momento es posible saber de qué instrumento de inscripción se trata a lo largo de la transcripción. No profundizo más en esta cuestión porque su complejidad rebasa los límites del presente artículo. Únicamente deseo señalar que no existe una relación de dependencia, en ningún momento, entre los instrumentos de inscripción (y/o las tintas o colores) y el proceso de creación. Es por ello que, en la transcripción final, dicho aspecto se relegó a un segundo plano y no cumple una función primordial en la misma.

Así pues, la transcripción final del primer cuaderno manuscrito de El libro vacío de Josefina Vicens, como se puede apreciar, terminó por ser de carácter híbrido; es decir, ha tenido que recurrir a soportes diversos tanto manuales como electrónicos, debido a vicisitudes de índole técnica, así como a las limitaciones provocadas por el confinamiento durante el último año. Por supuesto, una transcripción definitiva sólo se alcanzará una vez que sea publicada formalmente, lo cual supondrá su revisión final y, naturalmente, la incorporación del correspondiente aparato crítico.

A manera de conclusión de este apartado, es preciso señalar que, en última instancia, es el propio manuscrito, tal y como he procurado consignar a lo largo de este artículo, el que, eventualmente, hará manifiestas aquellas condiciones que deben enfatizarse y destacarse, y cuáles pueden dejarse en un segundo plano. Pero, ante todo, es a través de un dedicado y profuso proceso de transcripción -siempre orientado por el principio de repeticiónque los soportes se irán definiendo hasta poder establecer los más idóneos en estricto apego a la lógica interna del manuscrito en cuestión y de los fines que se persigan. Además, claro, de las condiciones de tiempo con que se cuente y de los recursos tecnológicos que se tengan a disposición. 
En cualquier caso, se debe tener presente que al emprender la transcripción de un manuscrito, más allá e independientemente de las preferencias que se tengan, es probable que sea necesario ajustar constantemente los objetivos y las características de la misma, entre los diversos soportes que se tengan a disposición, de manera constante. Sin duda, habrá manuscritos que se dejen transportar a lo electrónico, casi íntegros, sin dificultad. Pero igualmente habrá otros casos respecto de los que se tenga que discernir si son realmente trasportables a esos soportes o no, sin menoscabo de la fidelidad al documento original. O casos como el primer cuaderno manuscrito de El libro vacio, en que se tendrán que privilegiar algunos aspectos por sobre otros. Y en fin, muy bien puede ser que algunos manuscritos reclamen, como se ha hecho notar aquí, un tratamiento más manual que electrónico.

En palabras de Fernando Colla:

Son los rasgos propios de los documentos a publicar y del método de trabajo del autor que se trasluce en estos documentos los que determinan la calidad y cantidad de criterios que entrarán en juego en la definición de un esquema de presentación; son las finalidades del editor y las limitaciones materiales de la empresa las que condicionarán el grado de exhaustividad y los niveles de información que intervienen en dicho esquema. ${ }^{23}$

\section{Por un método apográfico en los estudios genéticos}

El presente artículo ha tenido como propósito central dar cuenta de la labor de transcripción del primer cuaderno manuscrito de El libro vacío. Dicho proceso procuró partir de una mirada libre de predeterminaciones con el fin de comprender los diversos aspectos que componen el documento y consolidar una forma de reproducción del mismo que fuera capaz de transmitir su esencia y sus rasgos más relevantes, sin deformarlo y siendo lo más fiel posible al original.

Como ha sido expuesto, en dicho proceso se presentaron diversas vicisitudes, mismas que provocaron la necesidad de realizar ajustes y replantear algunas labores. Los inconvenientes más importantes fueron, primero, las dificultades de orden técnico en relación con el uso de un soporte electrónico para la transcripción; y después, el surgimiento de la pandemia que es de todos conocida. Esta última circunstancia, al impedir la consulta de los manuscritos tal cual se venía realizando, provocó una transformación radical en el modo en que hasta ese momento se había concebido el trabajo de transcripción y, de manera más amplia, la propia investigación. Concretamente, la posibilidad de emprender una transcripción apógrafa del manuscrito, fue lo que permitió consolidar los criterios para la transcripción definitiva que, como se ha mencionado, terminó por definirse como diplomática e híbrida (se ocuparon soportes tanto manuales como electrónicos para su realización).

En ese sentido, a continuación se plantean algunas reflexiones en torno a la importancia que puede entrañar la realización de una transcripción apógrafa, en el proceso de edición genética de un manuscrito.

Lo primero es hacer constar que la tarea de copiar manualmente un manuscrito, con miras a su desciframiento y estudio, puede llegar a conformarse, con toda propiedad, en un método. Una práctica semejante abona en la comprensión de aspectos como las evoluciones de la escritura a lo largo del proceso de creación o,

\footnotetext{
${ }^{23}$ Colla, F. Op. cit., p. 153.
} 
incluso, del tempo y el ritmo que llega a tener la misma en diversos momentos. Lo cual comporta una enorme relevancia en la medida en que redunda necesariamente en una delimitación más precisa de las sucesivas y múltiples campañas de escritura que atraviesan el manuscrito.

Evidentemente estoy lejos de proponer que se realice, sin mayores reparos, una copia del manuscrito que es objeto de estudio. Por el contrario, tal posibilidad debe ser sopesada con serenidad en cada caso, a la luz del marco teórico y los objetivos que se persigan, y si las dimensiones lo permiten, debe considerarse seriamente el llevarla cabo. No obstante, aun suponiendo, por la razón que sea, que el manuscrito en cuestión no permita su reproducción completa manualmente, es recomendable que se realice la copia de una cantidad razonable de folios, fojas, páginas o fragmentos, según sea el caso, con el fin de emular los movimientos de escritura originales, en la medida de lo posible. Por mínima que sea, esta actividad reportará, sin lugar a ninguna duda, aprendizajes y percepciones novedosos, y hasta impensables a simple vista, respecto de un manuscrito y los innumerables fenómenos escriturales que lo conforman. Así, no es imposible que, según las características, la extensión del documento y el tiempo con que se cuente, quepa realizar la copia íntegra o de gran parte de un determinado manuscrito literario.

Ahora bien, el ejercicio de copia manual no resultará nada extraordinario para quienes han realizado investigaciones, dentro un archivo formal, en relación con manuscritos o con acervos literarios, porque saben que las condiciones de resguardo y conservación imponen estrictas normas de cuidado para la consulta de ese tipo de materiales (generalmente se exige el uso cubrebocas y se impide la introducción, en la sala de consulta, de cualquier instrumento de escritura que no sea un computador u hojas de papel en blanco y, únicamente, un lápiz, con el objeto de que los documentos no puedan ser inscritos o alterados). De tal forma, la copia manual de un documento constituye una de las actividades esenciales en el trabajo de archivo.

En otras palabras, el método apográfico que aquí se propone como parte de las labores de transcripción de un manuscrito, encuentra su origen, en última instancia, en una práctica consuetudinaria tanto en el ámbito de la crítica genética como de otras disciplinas como la historiografía: la consulta de acervos y archivos en instituciones expresamente diseñadas para ello.

Más allá, no se debe minimizar el hecho de que una práctica semejante procura restituir, en lo que respecta a la dimensión del sujeto, la centralidad y el protagonismo de las corporalidades que se ven involucradas en el propio proceso de transcripción (el cuerpo del transcriptor es igualmente existente). Así como busca privilegiar, en lo que respecta a la dimensión del objeto, una aproximación centrada en las materialidades de la escritura (el manuscrito es también otro cuerpo). Todo ello, por supuesto, sin olvidar el tercer cuerpo que conforma la obra en cuestión propiamente dicha. Por decirlo de algún modo, la pretensión de proponer un método apográfico radica en anteponer aquello que por la mano se piensa en la escritura, a todo aquello que, bajo la consagrada cultura visual que nos recorre, indefectiblemente procurará imponer el ojo. Y esto encuentra su fundamento último en al menos dos aspectos.

Por un lado, es importante enfatizar que, en el propio manuscrito -e igual en la novela, aunque en ésta en menor medida-, desde las primeras páginas se hace presente una preocupación fundamental respecto al cuerpo. La misma puede resumirse, hasta cierto punto, en un atormentado impulso que el propio el protagonista, José García, no comprende: una necesidad de escribir que lo sobrepasa y que sólo atina a explicarse como un acto 
involuntario, como una "gana del cuerpo", como un sentir que surge de la propia carne. Así, en determinado momento de la novela, José García escribe:

\begin{abstract}
Mejor una hoja nueva, limpia, y otra vez, lentamente, la mayúscula de gala. Allí empieza lo que unas horas después me habrá dejado exhausto. El cuerpo, que me acompañaba con tanta cordialidad, empieza a independizarse; los dedos de los pies se encogen nerviosamente; me recorre la espalda, a lo largo de toda la columna vertebral, una línea fría; me duele la nuca y dentro de la cabeza siento como una espiral que rápidamente gira tratando de encontrar algo, ese algo que exprese algo. ${ }^{24}$
\end{abstract}

Una cuestión que, si se observa con atención, abre por lo menos dos dimensiones de lo corpóreo en la propia escritura: la del personaje y la de su autora; dimensiones que permanentemente se manifiestan de manera simultánea. ${ }^{25}$

En segundo lugar, el fundamento para proponer un método apográfico en crítica genética, respecto de un manuscrito que se busca transcribir para su estudio y difusión, se encuentra en la propuesta de un renombrado académico como lo es Hans Ulrich Gumbrecht, en lo que llama, precisamente: "los poderes de la filología”. Dicho pensador, en respuesta a un texto de uno de sus más connotados colegas alemanes, Ottmar Ette, hace notar que, en tanto "ciencia del espíritu", la filología corre el riesgo de desmaterializar sus objetos de estudio, es decir, de anular su condición de objetos físicos en aras de una interpretación de los mismos. Literalmente, Gumbrecht señala:

deposito mis esperanzas en aquellas formas no interpretativas de ocuparse de objetos culturales que escaparían a la larga sombra de las Humanidades como Geisteswissenschaften, esto es, como "ciencias del espíritu" que desmaterializan los objetos a los que refieren y hacen imposible tematizar las diferentes inversiones que realiza el cuerpo humano en diferentes clases de experiencia cultural. ${ }^{26}$

Ciertamente, en ningún momento el profesor de Stanford sugiere emprender la copia manual de un manuscrito que se busca estudiar o editar -de hecho, no se detiene mayormente en los manuscritos en tanto objetos producidos manualmente. No obstante, hace notar la importancia que las dimensiones corporal, material y física, pueden llegar a tener en relación con el documento que se estudia, además de otros criterios fundamentales. El pensador alemán sostiene:

Lo que veo operando en las prácticas filológicas -como su lado oculto, vivo, y verdaderamente fascinante- es un tipo de deseo que, sea como sea que se manifieste, siempre excederá las metas

\footnotetext{
${ }^{24}$ VICENS, J. El libro vacío. México: FCE, 2011, p. 99.

${ }^{25}$ En estricto sentido, cabría hablar de cinco dimensiones en las que interviene el cuerpo: las dos ya mencionadas (personaje y autora), el cuerpo de la propia escritura en sus materialidades, el cuerpo de la obra formalmente publicada y, en fin, el cuerpo de quien estudia el manuscrito (el geneticista o filólogo).

${ }^{26}$ Gumbrecht, H. U. Los poderes de la filología. México: Universidad Iberoamericana, 2007, p. 20. Se trata de la respuesta al conocido texto de Ottmar Ette: La filología como ciencia de la vida.
} 
explícitas de las prácticas filológicas. Más aún, en cada caso específico, este deseo conjura el cuerpo del filólogo junto con la dimensión espacial que a primera vista parece ser ajena a cualquier clase de práctica académica dentro de las Humanidades. ${ }^{27}$

Por supuesto, lo que subyace a la propuesta de Gumbrecht es la cuestión nada sencilla de hasta dónde, en lo que respecta al quehacer filológico (o genético, como en el presente caso), cabe la interpretación del estudioso o del transcriptor y hasta dónde ésta sería inviable, en tanto termina por incidir e incluso trastocar el objeto de estudio. Al respecto, el académico señala: "ciertas decisiones filológicas tienen la estructura de un juicio estético, la estructura de decisiones que deben ser tomadas en situaciones en las que no hay evidencia disponible." ${ }^{28}$ No es, por ello, fortuito que proponga considerar al filólogo como un editor. Empero, enseguida puntualiza:

Los editores no deben nunca cruzar el umbral entre filología y Nachdichtung (imitación poética) -pero esto no puede implicar que estén siempre completamente dispensados de formular juicios estéticos, y mucho menos que puedan evitar producir efectos subjetivos. ${ }^{29}$

De tal forma, para Gumbrecht no es aceptable que el trabajo filológico se restrinja a una visión puramente "basada en el texto" o a la supuesta intencionalidad del mismo, porque eventualmente y de manera inevitable, se tendrán que abordar cuestiones que van más allá; aunque esto no debe traducirse en una especie de licencia para hacer del trabajo filológico una mera creación del propio filólogo. ${ }^{30}$

Así, a partir de tales planteamientos propongo considerar el realizar la copia a mano de un manuscrito -en todo o en parte- como una labor no sólo posible, sino incluso imprescindible para el estudio y análisis en relación con un determinado documento, aún más si se trata de un manuscrito literario y si se parte de una perspectiva crítico-genética.

En ese sentido, como comentario final, se aludirá brevemente a algunos planteamientos hechos por el pensador Byung Chul Han, en su libro Shanzhai, en la medida en que encuentran una correspondencia sumamente productiva y fértil en relación con lo que se ha expuesto en el presente artículo.

A lo largo de dicho libro, que es una reflexión de orden estético en relación con las obras artísticas y la forma en que son concebidas en la cultura china y en la cultura occidental, el autor de origen coreano sostiene la tesis de que el pensamiento chino es deconstructivo por definición, en comparación con el pensamiento occidental, que se encuentra profundamente ligado a las nociones de: ser, verdad y original. De tal forma, el primero sería proclive a la repetición, la copia y la falsificación; mientras que el segundo sería adepto al cultivo de la originalidad y la exclusividad.

\footnotetext{
${ }^{27}$ Ibídem, p. 18.

${ }^{28}$ Ibídem, p. 41.

${ }^{29}$ Ibídem, p. 41-42.

${ }^{30}$ Por supuesto, esta cuestión entraña una compleja serie de cuestiones adyacentes, que, por razones de espacio, no es posible abordar aquí. No obstante, resulta innegable que a la luz de propuestas como la de Gumbrecht, se hace posible partir de una concepción del trabajo filológico -en este caso, crítico-genético-, centrada en las materialidades y las corporalidades, mucho más dúctil de lo que permitirían las perspectivas tradicionales.
} 
Ahora bien, en el segundo capítulo del libro, que lleva por título: "Zhenji: Original”, se hace referencia a la noción de transcripción y se hace una serie de reflexiones sumamente interesantes en torno a ella. A continuación se reproduce un pasaje más o menos extenso de dicho capítulo. El propósito no radica más que en llamar la atención de que el método apográfico que se ha propuesto aquí, posee algo más que un mero parecido con las ideas del pensador coreano. A la letra, casi al inicio del segundo capítulo, se lee:

En chino clásico, el original se denomina zhenji. Literalmente significa "huella verdadera". Se trata de una huella singular, puesto que no tiene lugar en una trayectoria teleológica. $\mathrm{Y}$ en su interior no está habitada por ninguna promesa. [...] Más bien deconstruye toda idea de un original que encarna una presencia y una identidad invariables e inconfundibles que descansan en sí mismas. El proceso y la diferencia le confieren una fuerza centrífuga deconstructiva. No da lugar a ninguna obra de arte acabada, cerrada en sí misma, que pudiera adoptar una forma definitiva y escapar a toda transformación. Su diferencia respecto de sí misma no le permite alcanzar el reposo que le podría proporcionar una forma definitiva. En este sentido, siempre se aparta de sí misma. La concepción china del original como huella (ji) remite a la estructura freudiana de la "huella mnémica", que está sometida a un reordenamiento y transcripción constantes. La idea del original chino no se entiende como una creación única sino como un proceso infinito, no apunta a la identidad definitiva sino a la transformación incesante. ${ }^{31}$

La resonancia con algunas de las aspiraciones más profundas de la crítica genética es simplemente asombrosa. Sustitúyase, si no, la palabra "original” por el término "manuscrito" y se advertirán las correspondencias: ¿no cabe pensar en el manuscrito justamente como una "huella verdadera" de la obra literaria, que la deconstruye y la hace diferir de sí misma constantemente?

Un poco después, Han agrega:

Una obra de arte china nunca permanece idéntica a sí misma. Cuanto más venerada, más cambia su aspecto. Los expertos y coleccionistas escriben sobre ella. Se inscriben en la obra por medio de marcas y sellos. De esta manera, se van superponiendo inscripciones, de igual manera que las huellas mnémicas en el aparato psíquico. La propia obra está en transformación constante, sometida a una transcripción incesante. Esta no descansa en sí misma. Más bien fluye. Se opone a la presencia. La obra se vacía convirtiéndose en un lugar que genera y comunica inscripciones. Cuanto más famosa es una obra, más inscripciones muestra. Se presenta como un palimpsesto. ${ }^{32}$

El método apográfico que se ha propuesto en el presente artículo, en tanto parte esencial de la elaboración de una edición genética de un manuscrito literario, debe entenderse, en última instancia, precisamente como el emprendimiento de una transcripción incesante que, sin abandonar los límites de un riguroso quehacer científico,

\footnotetext{
${ }^{31}$ HAN, B. Shanzhai. El arte de la falsificación y la deconstrucción en chino. Traducción: Paula Kuffer. Buenos Aires: Caja Negra Editora, 2017, pp. 20-21.

${ }^{32}$ Ídem, p. 21.
} 
sea capaz de redimensionar los senderos hermenéuticos que, respecto de un texto literario y su proceso de creación, es posible transitar.

\section{Bibliografia}

BLECUA, A. Manual de crítica textual. Barcelona: Edhasa, 2018.

Colla, F. "La edición genética: entre la profusión y la mesura”. En: Colla, F. (comp.). Archivos. Cómo editar la literatura latinoamericana del siglo XX. Poitiers: Centre de Recherches Latino-Americaines, CRLA Archivos, 2005.

DÍAZ, A. Manual de edición crítica de textos literarios. México, UNAM, 2003.

ETte, O. y S. UgAlde (Coords.). La filología como ciencia de la vida. Ciudad de México: Universidad Iberoamericana, 2015.

Gumbrecht, H. U. Los poderes de la filología. Traducción: Aldo Mazzucchelli. México: Universidad Iberoamericana-Departamento de Historia, 2007.

HAN, B. Shanzhai. El arte de la falsificación y la deconstrucción en chino. Traducción: Paula Kuffer. Buenos Aires: Caja Negra Editora, 2017.

HAY. L. "La escritura viva", en LOIs, É. (coord.). Filología. Número especial dedicado a la Crítica Genética. Año XXVII, 1-2. Buenos Aires: Instituto de Filología y Literaturas Hispánicas “Dr. Amado Alonso”, 1996, pp. 5-22.

HIgASHI, A. Perfiles para una ecdótica nacional. Crítica textual de obras mexicanas de los siglos XIX y XX. México, UNAM/UAM, 2013.

LOIS, E. Génesis de escritura y estudios culturales. Buenos Aires: Edicial, 2001.

PINO, C. y R. ZULAR. Escrever sobre escrever. Uma introdução crítica à crítica genética. São Paulo: WMF Martins Fontes, 2007.

RAMíREZ, I. "Genética y crítica textuales en la edición de obras contemporáneas." En: CLARK, B. et al (orgs.). Crítica textual: un enfoque multidisciplinario para la edición de textos. México: Colmex-UNAM, 2009.

VICENS, J. El libro vacío. Los años falsos. México: FCE, 2011. 